\title{
Peranan Unit Pengelola Kegiatan PNPM Mandiri dalam Meningkatkan Kesejahteraan Masyarakat
}

\section{The Role of the PNPM Mandiri Activity Management Unit in Enhancing Community Empowerment}

\author{
Marlina Sinaga*, Usman Tarigan \& Rosmala Dewi \\ Program Studi Administrasi Publik, Fakultas Ilmu Sosial Dan Politik \\ Universitas Medan Area, Indonesia
}

Diterima: Mei 2019; Disetujui: Juni 2019; Dipublish: Juni 2019

\begin{abstract}
Abstrak
Di lingkungan masyarakat, masih banyak ditemukan keluhan masyarakat dalam hal kesejahteraan hal ini peranan pemerintah yang masih kurang tepat sasaran. dengan melaksanakan tugas dan tanggung jawab kepada masyarakat seharusnya setiap pemerintah memiliki kemampuan untuk lebih meningkatkan kualitas pelayanan seperti yang telah ditetapkan oleh istansi pemerintah. Di Kecamatan Pangururan Kabupaten Samosir sangat di harapkan untuk meningkatkan mutu kualitas kinerja pemerintah yang lebih bertanggung jawab sebagaimana telah ditetapkan oleh pemerintah dalam melayani masyarakat. Dalam hal ini yang menjadi perumusan masalah adalah bagaimana peranan UPK PNPM Mandiri dalam meningkatkan kesejahteraan masyarakat di Kecamatan Pangururan Kabupaten Samosir. Adapun tujuan penelitian ini adalah untuk mengetahui bagaimana UPK PNPM Mandiri menjalankan program SPP di Kantor UPK PNPM Mandiri di Kecamatan Pangururan Kabupaten Samosir. Metode dalam penelitian ini adalah kualitatif dengan mengunakan teknik observasi, wawancara dan dokumentasi. Berdasarkan hasil penelitian ini di lanjutkan dengan menganalisa data yang di peroleh, maka hasilnya yaitu peranan UPK PNPM Mandiri dalam meningkatkan kesejahteraan masyarakat di kantor UPK PNPM Mandiri di Kecamatan Pangururan Kabupaten Samosir dikatakan baik. Dapat dilihat dengan peran UPK PNPM Mandiri yang menjalankan tugas dan fungsi dengan baik sesuai dengan standar alur prosedur.
\end{abstract}

Kata Kunci: Peranan, Unit Pengelola Kegiatan, Kesejahteraan Masyarakat

\begin{abstract}
In the community there are still many publik complaints in terms of the role of govrmment, which is still not well targeted by carrying out duties and responsibilities to the community should every govermment have the ability to further improve the quality of service. As determined by the governement agenciens in the districk pangururan Samosir districk is expected to improve the quality of the government's more responsible performance as by the government in serving the community. In this case formulation of the formulation of the problem is how the role unit manager activities (upk) pnpm indendent in improving the welfare of society therough savings and loan lending as for the purpose of this study is to find out how UPK PNPM independent office in pangururan district samosir districk. The method in this research is qualitative by using technique of observation, interview and documentation based on the result is this study followed by analyzing the data obtained, then the result is the role of independent upk pnpm in improving the welfare of the community in the districk pangururan samosir districk can be said either. Seen from the progressof members of the spp group as well as, the role of independent UPK PNPM corres panding to the soup. Role
\end{abstract}

Keywords: Role, Activity Management Unit, Community Welfare

How to Cite: Sinaga, M. Tarigan, U. Dewi, R. (2018). Peranan Unit Pengelola Kegiatan PNPM Mandiri dalam Meningkatkan Kesejahteraan Masyarakat, PERSPEKTIF, 7 (2): 46-49.

${ }^{*}$ Corresponding author:

ISSN 2085-0328 (Print)

E-mail:marlina12@gmail.com 


\section{PENDAHULUAN}

Unit pengelola kegiatan (UPK) adalah unit yang mengelola operasional kegiatan PNPM Mandiri pedesaan di kecamatan dan membantu BKAD mengoordinasikan pertemuan-pertemuan di kecamatan. Secara umum UPK PNPM Mandiri mempunyai peranan yang sangat penting bagi masyarakat untuk membantu dalam meningkatkan kesejahteraan masyarakat. UPK juga mempunyai tugas dan tanggung jawab terhadap seluruh pengelolaan dana PNPM Mandiri pedesaan di kecamatan Pangururan, serta pengelolaan administrasi dan pelaporan seluruh transaksi kegiatan PNPM Mandiri pedesaan dengan melakukan sosialisasi kepada masyarakat dan menegakkan prinsipprinsip PNPM Mandiri pedesaan dalam perencanaan, pelaksana dan pelestarian PNPM Mandiri pedesaan bersama dengan pelaku lainnya atau masyarakat setempat.

Sesuai ketentuan umum pasal 1 pada undang-undang Nomor 11 tahun 2009 tentang kesejahteraan sosial, kesejahteraan sosial adalah kondisi terpenuhinya kebutuhan material, spiritual, dan sosial warga Negara agar dapat hidup layak dan mampu mengembangkan diri, sehingga dapat hidup layak dan dapat melaksanakan tugas dan fungsi sosial.

Penyelenggaraan kesejahteraan sosial adalah upaya yang terarah, terpadu dan berkelanjutan yang dilakukan pemerintah, pemerintah daerah, dan masyarakat dalam membentuk pelayanan sosial dan/atau seseorang yang berkerja baik di lembaga pemerintahan maupun swasta yang ruang lingkup kegiatannya di bidang kesejahteraan sosial. kecamatan Pangururan kabupaten Samosir unit pengelola kegiatan (UPK) PNPM Mandiri merupakan program pemerintah untuk mengelola sumber dana keuangan desa untuk membantu masyarakat dalam meningkatkan kesejahteraan masyarakat baik secara ekonomi maupun pendidikan. Dengan adanya Peranan UPK PNPM Mandiri diharapkan dapat membantu masyarakat di kecamatan Pangururan agar masyarakat bisa meningkatkan pendapatan perekonomian dengan memanfaatkan potensi alam yang dimiliki di Kecamatan Pangururan Kabupaten Samosir untuk dijadikan sebuah pemicu untuk meningkatkan perekonomian masyarakat dan baik pemerintah maupun masyarakat harus $\begin{array}{lcc}\begin{array}{l}\text { bekerjasama } \\ \text { kesejahteraan } \\ \text { masyarakat }\end{array} & \begin{array}{c}\text { mewujudkan } \\ \text { serta demi }\end{array} \\ \text { Kabupaten Samosir yang lebih maju lagi. }\end{array}$

\section{METODE PENELITIAN}

Dalam penelitian ini jenis metode yang digunakan penelitian adalah dengan pendekatan kualitatif yang berfokus kepada peranan unit pengelola kegiatan (UPK) program nasional pemberdayaan masyarakat (PNPM) Mandiri dalam meningkatkan kesejahteraan masyarakat.

Menurut Sugiyono (2016) metode penelitian kualitatif adalah metode penelitian yang berlandasan pada filsafat postpositivisme, digunakan untuk melihat pada kondisi obyek yang alamiah (sebagai lawananya adalah eksperimen) dimana penelitian adalah sebagai instrument kunci, pengambilan sampel sumber data dilakukan secara purposive dan snowball, teknik pengumpulan dengan triangulasi (gabungan), analisis data bersifat kualitatif/induktif dan hasil peneliti kualitatif lebih menekankan makna dari pada generasilisasi. Lokasi penelitian dilakukan di kantor UPK Kecamatan Pangururan kabupaten Samosir. Pengumpulan data dilakukan dengan teknik wawancara. Wawancara ditunjukkan kepada anggota UPK PNPM Mandiri di Kecamatan Pangururan. Data yang sudah terkumpul akan dianalisis dengan teknik deskriptif kualitatif. Pemakaian teknik ini relevan dengan fokus permasalahan dan tujuan penelitian, yakni untuk menguraikan peranan UPK PNPM Mandiri dalam meningkatkan kesejahteraan masyarakat.

\section{HASIL DAN PEMBAHASAN}

Kecamatan Pangururan adalah sebuah kecamatan di kabupaten Samosir Sumatera Utara Indonesia. Pangururan juga merupakan ibu kota Kabupaten Samosir yang mempunyai 28 desa Tahun 2018. Dengan Kondisi Geografis kecamatan Pangururan Letak geografis: 20322045 lintang Utara, Luas daratan: $121.43 \mathrm{~km}^{2}$, Ketinggian: $04-2.157 \mathrm{~m}$ dpl. Dengan batas kecamatan Pangururan Sebelah Utara: kecamatan Simanindo, Sebelah Selatan: kecamatan Palipi, Sebelah Barat: kecamatan Sianjur Mula-mula, Sebelah Timur: kecamatan Ronggur Nihuta.

Dengan Kependudukan: Jumlah penduduk: 35.178, Laki-laki: 17.664 Jiwa, 
Perempuan: 17.514 Jiwa, Kepala keluarga: 8.507 kk. Serta pekerjaan yang dilakukan masyarakat di Kecamatan Pangururan adalah yang mayoritas $75 \%$ sebagai petani( padi, kopi, berdagang dan menangkap ikan) 5\% guru tetap, $5 \%$ guru honor, $5 \%$ pegawai ASN, $2 \%$ sebagai pegawai swasta, $3 \%$ sebagai polisi, 3\%tukang becak dan 2\% TNI.

Masyarakat di kecamatan Pangururan pada umumnya mayoritas memiliki perkerjaaan sebagai petani (padi, jagung dan kopi) yang mengharapkan hasil yang mereka tunggu untuk dijual. Sebelum adanya UPK PNPM Mandiri masyarakat memang mendapatkan bantuan dari pemerintah daerah yang disalurkan melalui kepala desa yang berupa beras raskin, hal ini membuat masyarakat belum mendapatkan arti dari kesejahteraan sesungguhnya karena masyarakat menginginkan pemerintah mampu mengubah cara kerja dalam membantu kesejahteraan masyarakat.

UPK dalam menyelenggarakan sistem kinerja yang baik dan tepat sasaran UPK melakukan sistem yang terarah, terpadu, menyeluruh dan tanggap terhadap perubahan yang akan muncul di kemudian harinya. Hal tersebut dimaksudkan agar pelaksanaan TIM mampu bekerja sama dengan baik. Baik anggota TIM lainnya maupun kelompok swadaya masyarakat.

Agar tercapainya tujuan untuk meningkatkan kesejahteraan masyarakat maka dilakukan pengawasan program pemberdayan masyarakat di Kecamatan Pangururan.. BKAD adalah lembaga yang dibentuk atas dasar kesepakatan antara desa didalam satu wilayah dalam satu Kecamatan dan antar Kecamatan yang mempunyai fungsi perencanaan strategis, fungsi pengelolaan kegiatan dan fungsi pengawasan dalam pengelolaan kegiatan dan fungsi pegawasan dalam pengelola micro finance, pelaksanaan program dan pelayanan usulan kelompok. Masalah kemiskinan bukan hanya terjadi di perkotaan tetapi juga terjadi di desa khususnya di kecamatan pangururan kemiskinan yang terjadi didesa mengakibatkan masyarakat Pangururan menjadi semakin terbelakang dalam segala keterbatasan yang ada termasuk juga dalam keterbatasan perekonomian. Dengan kondisi seperti ini mengakibatkan masyarakat Pangururan menjadi mengharapkan bantuan dari pemerintah dalam hal kesejahteraan masyarakat.

Adanya program UPK PNPM Mandiri di Kecamatan Pangururan dalam meningkatkan kesejahteraan masyarakat dapat memecahkan masalah suatu desa dan dengan pemberdayaan masyarakat simpan pinjam perempuan masyarakat di Kecamatan Pangururan akan terbantu dan meningkat melalui kegiatan yang dilakukan oleh anggota UPK PNPM Mandiri Pangururan dan masyarakat di Kecamatan Pangururan.

Adapun Faktor Pendukung Dan Pengambat Unit Pengelola Kegiatan (UPK) PNPM Mandiri.

Penelitian yang dilakukan oleh penulis tentang peranan unit pengelola kegiatan pnpm mandiri di kecamatan pangururan memiliki beberapa poin penting terkait dengan faktor yang mendukung pelaksanaan kegiatan berikut ini ada beberapa faktor pendukung peran upk pnpm mandiri di kecamatan pangururan: a) Adanya informasi yang diberikan oleh UPK PNPM Mandiri kepada masyarakat setempat; b) Adanya rasa ingin maju dari masyarakat dalam meningkatkan perekonomian masyarakat di kecamatan pangururan. Hal ini diperkuat dari penelitian saat wawancara dengan seorang anggota simpan pinjam perempuan yang mengaku bahwa uang tersebut memang di pergunakan untuk kebutuhan modal dan pendidikan anaknya.

Adapun penghambat yang peneliti dapatkan memiliki poin penting yang menjadi penghambat dalam proses peran unit pengelola kegiatan pnpm mandiri di kecamatan pangururan adalah sebagai berikut: a) Kurangnya koordinasi dari pihak pemerintah kepada UPK PNPM Mandiri; b) Pemerintah telah mengurangi kegiatan UPK PNPM Mandiri; c) Adanya keterlambatan pencairan dana bergulir; d) Adanya berkas proposal yang tidak memenuhi standar.

UPK dalam menyelenggarakan sistem kinerja yang baik dan tepat sasaran UPK melekukan sistem yang terarah, terpadu, menyeluruh dan tanggap terhadap perubahan yang akan muncul di kemudian harinya. Hal tersebut dimaksudkan agar pelaksanaan TIM mampu bekerja sama dengan baik. Baik anggota TIM lainnya maupun kelompok swadaya masyarakat. 
Seperti hasil wawancara yang dilakukan penulis dengan Bapak Hontal Sinurat selaku ketua UPK PNPM Mandiri kecamatan pangururan, mengungkapkan bahwa: Jika berbicara tentang peran UPK PNPM Mandiri saya mengatakan UPK ini sangat berperan dalam membantu masyarakat yang masih kurang mampu, hal ini dapat dilihat dari segi perekonomian masyarakat, dengan adanya sosialisasi dari UPK PNPM Mandiri masyarakat mengetahui mengenai planing kedepannya itu seperti apa (Jumat, 9 februari 2018 pukul 11:05 WIB).

Begitu juga dengan wawancara yang dilakukan penulis dengan Ibu Sitanggang seorang warga desa Saitnihuta seorang anggota kelompok simpan pinjam perempuan (SPP) mengatakan bahwa: "Saya selaku anggota kelompok SPP, menurut saya UPK sangat berperan penting di kampung kami (Desa Saitnihuta) karena UPK membantu kami dalam mencari jalan keluar saat kami kesulitan perekonomian melalui simpan pinjam perempuan. (Sabtu, 10 februari 2018 pukul 15:40 WIB)."

\section{SIMPULAN}

Simpan pinjam perempuan adalah salah satu program kerja dari UPK PNPM Mandiri di Kecamatan Pangururan Kabupaten Samosir dengan tujuan membantu masyarakat khususnya di Kecamatan Pangururan. Dengan adanya simpan pinjam perempuan (SPP) masyarakat merasa terbantu dalam bidang perekonomian. Simpan pinjam perempuan di Pangururan sendiri terlihat lebih berkembang dan lancar dalam pembayaran peminjaman dana bergulir di banding tahun sebelumnya, oleh karena itu kelompok SPP sendiri sangat terbantu dengan adanya program UPK PNPM Mandiri.

Dengan adanya simpan pinjam perempuan (SPP) di Pangururan dapat dilihat sebagai berikut: a) Masyarakat terbantu dalam mengelola keuangan dengan tujuan meningkatkan kesejahteraan; b) Perubahan perekonomian masyarakat cukup baik di bandingkan tahun sebelum adanya kelompok SPP; c) Para wanita khususnya (Ibu rumah tangga) lebih mandiri dalam mengelola keuangan serta mengembangkan usaha mereka; d) Dengan adanya simpan pinjam perempuan dapat membantu pendidikan anak.

\section{DAFTAR PUSTAKA}

Arikunto. (2006). Manajemen Penelitian. Jakarta: Rineka Cipta

Departemen Dalam Negeri 2007. PTO PNPM-MP. Jakarta: Tim koordinasi PNPM-MP.

Dwidjowijojo, R.N. (2003). Kebijakan Publik Formulasi, Implementasi dan Evaluasi (Public Policy). Jakarta: Elek Media Komputindo

Eliyanti. (2012). Upaya PNPM Mandiri dalam Meningkatkan Kesejahteraan Masyarakat di Desa Kebuyutan Kecamatan Tirtaya Kabupaten Serang. Skripsi Fakultas Ilmu Dakwah dan Ilmu Komunikasi Universitas Islam Negeri Syarif Hidayatullah Jakarta

http://googeleweblight.com. (diakses, Jumat 28 Agustus 2015, Pukul 13:36 WIB)

http://id.wikipedia.org/wiki/pnpm _mandiri_pedesaan.(diakses, Rabu 1Maret 2017, Pukul 09:47)

http://m. elshinta. Com. (diakses, Senin 13 Februari 2017, Pukul 21:34WIB)

http://pnpmtamanrajo.wordpress.com.(diakses, senin 25 Oktober 2010, pukul 16:31WIB)

http://www.mi zibur. (diakses, 11 Januari 2014, Pukul 11.00 WIB)

Isbandi, A.R. (2008). Intervensi Komunitas Pengembangan Masyarakat Sebagai Upaya Pemberdayaan Masyarakat.Jakarta, PT Raja Grafindo Persada.

Kadir, A. (2012). Pengantar Teori Pembangunan. Medan, Pustaka Bangsa Press

Marpaung, O.K.D. (2017). Implementasi Program Pembangunan Infrastruktur desa dalam Meningkatkan Kesejahteraan Masyarakat di kec. Angkola.Skripsi Fisip Universitas Medan Area

Nugroho, I. (2012). Pembangunan wilayah: perspektif ekonomi, sosial

Peraturan Presiden No. 2 Tahun 2015 Tentang Arah kebijakan Bidang Desa dalam RPJM (Rencana Pembangunan Jangka Menengah Nasional) 2015-2019

Siagian, S.P. (2009). Adminstrasi pembangunan. Jakarta: PT Bumi Aksara

Soekanto, S. (1982). Sosilogi suatu pengantar. Jakarta: CV Rajawali Pers

Sugiyono. (2006). Metode Penelitian Administrasi. Bandung: CV. Alfabeta Jakarta Erlangga

Sugiyono. (2016). Metode Penelitian Pendidikan. Bandung: CV. Alfabeta Bandung

Tangkilisan (2003). Konsep Kebijakan Publik. Penerbit PT.Gramedia Pustaka Utama

Undang-Undang No. 11 Tahun 2009 Tentang Kesejahteraan Sosial

Undang-undang No. 32 Tahun 2004 Tentang Pemerintahan Daerah. 